\section{BLOOD AND BONE MARROW PATTERNS}

By G. D. TAlbotT, M.D., E. R. Hunsicker, B.S., and J. LI, M.D. Pp. 59, fully coloured. New York and London: Grune and Stratton Inc. 1957. \$12.

The authors aimed at presenting blood cell patterns as seen by bone marrow aspirations, using coloured photomicrographs. They believed that such a plan would be helpful for ordinary practitioners, students and technicians, as well as for the training programme of haematologists.

The arrangement of this book is very attractive; on the right-hand side are the pictures and on the left a few words conveying the salient features. The greater part of the illustrations are very fine, well-reproduced coloured photomicrographs, but there are a few which are below the general high standard. Unfortunately the text does not match the lovely pictures. Didactically it is wrong to say that in red cells the "nucleus is no longer visible'; they simply have none. The Auer body shown in a promyelocyte on page 6 is nothing like any I have ever seen in smears or in illustrations, but the rod-like structure shown nearby may be one. The caption on platelets suggests that they are fragments of cytoplasm; but they contain nuclear constituents also. The representatives of the plasma cell series are most unhappily chosen; they are far from typical examples and do not match the description given. The term 'myelogenous' leukaemia, particularly when followed by 'lymphatic' is odd; why not ' myeloid ' or alternatively ' lymphogenic'? The inclusion of a pageful of illustrations of smear preparations from giant follicular lymphoma is one of the most daring undertakings in a book devoted to teaching. This condition cannot be recognized by anything other than a histological section. Follicles become disrupted in smears, and their giant form cannot be appreciated even in imprint preparations. The page on infectious mononucleosis is most unhelpful. The captions point out the atypical lymphocyte but do not mention ' mononuclears.' This is, of course, as one sees it in blood and marrow, but it suggests that tie term ' glandular fever' is preferable in this most pleomorphic of all blood patterns. One wonders if the authors have ever considered Downey's classification of glandular fever cells as worthy of adoption. The plate on extramedullary haematopoiesis (why not ' haemopoiesis'?) is most ill-advised. Metamyelocytes can be found in almost any normal blood smear, if you only look long enough; nucleated red blood cells are found in blood normally after exercise; and the two photographs of isolated islands of haemopoiesis in marrow are not at all convincing, they show fat and fibrous tissue, but no haemopoiesis, whether intra- or extra-vascular.

This book will be widely appreciated and it will, one hopes, stimulate interest in haematological morphology, a subject so often decried by our more chemically-minded colleagues who should be pitied as they miss the beauties of a well-stained microscopical preparation.
E.N.

\section{A MENTAL HEALTH HANDBOOK}

By IAN SKotTowe, M.D., M.R.C.P., D.P.M. Pp. vii + 196. London: Edward Arnold Ltd.气 I957. 2 Is.

This has been a boom year for mental health $\vec{\Rightarrow}$ In addition to the publicity afforded by the series of broadcasts on both television and radio earlier in the year, the exhibitions now touring the provinces $\frac{\overline{0}}{x}$ and the 'open-days' organized by recruitment $-\vec{\sigma}$ minded superintendents of mental hospitals, thereo has been a large number of popular books on psychiatry (but masquerading under various names)published in the last 12 months. While the public appetite appears to be insatiable, there are signs $\overrightarrow{-}$ that the medical reader has reached a surfeit. $\omega^{\omega}$ This a matter for regret, for among the flood of 'Teach Yourself Nerves' books are a number of serious works which make a distinct contribution to medical literature.

Such a book is Dr. Skottowe's handbook. I $\dot{\omega}_{\infty}$ commences with a lucid introduction to the mentak health services and then defines mental health as a concept of social adaptation. Psychological features of the organism homo sapiens are then described? followed by a consideration of its interaction withthe environment. Varieties of mental illness are briefly but sympathetically enumerated, togethere with an assessment of some social implications of them. The final two chapters make an originab contribution to the subject by discussing mentaf hygiene and making pertinent and soundly formm $\overrightarrow{0}$ lated suggestions regarding the future organization training, education and research in mental healt

The auihor writes clearly and concisely. He haso obviously thought very deeply on the subject, and provides us in three easily digested stages with के comprehensive overview of mental health-first the background of hard facts, then the problems of psychiatry in its setting of social medicine, and finally suggestions and recommendations aimed ae finding solutions. He has a very clear insight into the role which workers on the medical fringe can adopt-those psychologists, P.S.W.s, M.H.O.s, etc. who play an increasingly important part in what the Lancet calls 'Greater Medicine'. We live in time of expanding medical horizons, and an authos who can provide us with such well-surveyed route map deserves our consideration. This book is directed at a very wide audience - to all those, in fact, who share in the professional task of humano health and social welfare, and it is to be hoped that many will accept the challenge which it offers.

\section{BCG \& VOLE VACCINATION}

By K. Neville Irvine, M.A., D.M., B.Ch.) M.R.C.S., L.R.C.P. Second Edition. Pp. ro with ro coloured illustrations. London: NAPT 1957. I5s.

This new edition of the excellent handbook first published in 1954 is especially welcome since in recent years considerable progress has been made्? 